Ralph Kattenbach, Barbara Kump, Johannes Moskaliuk*

\title{
New Work Arrangements - A Review of Concepts and Theories
}

Much has changed since Frithjof Bergmann's seminal thoughts on New Work (1994; 2004): For example, mobile devices as well as virtual communication and cooperation have entered the business world and have brought forth a new economy, agile work processes, new employment relationships, leadership styles, co-working tools, and an enhanced spatial and temporal flexibility (for a review, see Aroles et al., 2019). The present special issue on "New Work Arrangements" was initiated to revise and refine the underlying concepts and theories to account for these path-breaking developments. When we made our call for submissions in late 2019, our main observation was that research on work and leadership has been neglecting the pervasive presence of technology in organizational work (Orlikowski \& Scott, 2017). We argued that these changes in work methods and organization are so profound that common theories and concepts need to be revisited to see if they still do justice to the changed situation. Shortly thereafter, the world was hit by the global COVID-19 pandemic. The corresponding restrictions on social contact and mobility catalysed, whether desired or not, the widespread use of virtual collaboration and communication tools, as well as flexible work arrangements that account for the various needs and duties of employees' private lives (e.g., home-schooling). Much of what has been unthinkable in advance (e.g., video conferences instead of business trips, flexible forms of mobile work or home office) has proven beneficial for companies as well as employees. Hence, in the 'new normal' of the aftermath of the COVID-19 crisis in Western industrialized nations, it seems clear that many of the new approaches will be maintained. Revisiting forms of New Work, as well as related challenges and opportunities, is now more important than ever.

The present special issue on "New Work Arrangements" provides insights into the diverse influences of digitization on the way we organise, lead, and learn. It includes perspectives from various disciplines, and using different methods, incorporates characteristics of New Work Arrangements in existing theories, models, and concepts. Accordingly, articles from the special issue are assigned to three categories: (1) New Organization, (2) New Leadership, and (3) New Learning.

* Prof. Dr. Ralph Kattenbach: International School of Management, Hamburg. E-Mail: ralph.kattenbach@ism.de.

Dr. Barbara Kump: WU Vienna University of Economics and Business. E-Mail: bkump@wu.ac.at.

Prof. Dr. Johannes Moskaliuk: International School of Management, Stuttgart. E-Mail: johannes.moskaliuk@ism.de.

mrev, 32 (4) 2021, $297-301$

DOI: 10.5771/0935-9915-2021-4-297 


\section{New Organization}

Digital technologies have led to the emergence of novel organization methods. In particular, New Work environments have spurred the emergence of more 'agile' organizational forms that are based on self-organization and distributed responsibility. One of these new approaches is the management system Holacracy. In the first article of our special issue, Maria Farkhondeh and Barbara Mueller subject the promises of Holacracy to a critical analysis. They ask: "What is new about Holacracy?" and apply qualitative content analysis to Brian Robertson's (2015) Book "Holacracy - The Revolutionary management system that abolishes hierarchy" to identify its key characteristics. Then, they assess these characteristics against the backdrop of five key management dimensions: specialization, decision autonomy, participation, formal standardization, and punishment, to position the concept of Holacracy on the continuum between bureaucratic and post-bureaucratic approaches. They conclude that Holacracy as a management system is still bureaucratic through its high degree of formal standardization; yet it comes with certain modifications, especially on the level of decision-making autonomy.

In addition to new forms of organizational structures, digitisation has enabled new business models and strategies; however, these also come with numerous behavioural and organizational challenges for firms. For example, online markets for talent and labour allow firms to outsource complex tasks but may have implications for knowledge and human resource management. Adoption of digital technologies may require complementary investments in rare skills to bring about the intended productivity improvements in full (Leiponen et al., 2016). In this context, the article by Anja Schmitz, Kirsten Wüst, and Lydia Fritz examine New Work attributes in job advertisements. The authors show that millennials perceive a higher organizational attractiveness if New Work attributes like self-determined work or continuous feedback are listed in a job posting. New Work attributes (compared to traditional job attributes) influence their intention to pursue an application. Among millennials, New Work attributes in job advertisements lead to a perceived better fit with the company, which in turn leads to an increased likelihood of applying.

\section{New Leadership}

New technologies enable arrangements that offer work-life flexibility. However, studies have shown that such arrangements do not necessarily benefit all groups of workers equally (Kossek \& Lautsch, 2017) and may come with new challenges like blurring work-life boundaries or protecting leisure time and psychological detachment. Moreover, New Work arrangements may require new forms of leadership (Banks et al., 2019; Sheninger, 2019). In addition, leaders may have to overcome challenges in organizational identity, practice, and knowledge that occur when organizations become increasingly digitized (Kump, 2019). 
The article by Mariano Gentilin and Maria Alejandra Garcia-Madrigal poses the question of how to shape leadership in a virtual context. Based on a literature review, they propose a shared leadership solution focusing on communication, trust, and team cohesion. The paper highlights and characterises these factors, as well as the actions that should be taken to manage them. In this vein, digitization requires and promotes the empowerment of the team to interact in genuine collaboration. As a practical contribution, the authors present a scheme to analyse and manage virtual leadership in a company.

Furthermore, through the advent of digital technologies, virtual work has become the new normal: Staff members work from dispersed locations and interact through their smartphones or other mobile devices (Raghuram et al., 2019). The special issue addresses this particular aspect of smartphone usage: Ute Rademacher, Ulrike Weber, and Cassandra Zinn focus on informal rules and social practices that are established in the work-related use of smartphones. Since professional use of the smartphone can significantly blur the line between work and leisure, communication rules are important to ensure psychological detachment after working hours. The authors make clear that changes in the world of work do not only depend on conscious decisions; unconscious and unreflected organizational learning and adaption processes also deal with new technologies. For management, it is important to keep an eye on these developments and, if necessary, react with formal measures. Addressing the learning and adaptation process and management's response to it leads into our third focus area of New Learning.

\section{New Learning}

Digital devices, virtual reality and other innovative technologies provide New Learning opportunities for workers at their workplaces (Noe, Clarke \& Klein, 2014). These new situations require new management skills and may benefit from novel educational settings. Managers may need dynamic managerial capabilities to keep up to date with constant change (Helfat \& Martin, 2014) and handle emerging informal rules. At the same time, there are completely new design possibilities and thus questions of learning ergonomics. The article by Ulrike Weber, Malte Lömker, and Johannes Moskaliuk, for instance, examines the possible uses of chatbots in automated goal-focused coaching and thus provides a small glimpse into future developments. Although coaching is characterized by highly individualized human interaction that cannot be automated as a whole, the adoption of single aspects by chatbots is feasible. However, the acceptance of the use of technology on the part of the coachees remains questionable, which also raises the question of the success criteria of such automated coaching. Is the interaction with a human-looking, anthropomorphic chatbot perceived as more pleasant? In an experiment, the authors compare the effect of coaching chatbots with high and low anthropomorphism showing that high anthropomorphism leads to higher 
satisfaction with the coaching, higher confidence and higher effectiveness compared to low anthropomorphism.

\section{Conclusion}

The special issue has addressed a number of important topics in New Work Arrangements regarding the areas of organization, leadership, and learning. Nevertheless, other relevant topics mentioned in our call for contribution remain unaddressed, such as the acceptance of artificial intelligence in the workplace, or the potential of digital tools and methods to transfer knowledge, support self-reflection, and foster creativity. Future work may be dedicated to studying these technological developments, which have the potential to spur profound transformations in a wide range of HR and organization processes. Moreover, the COVID-19 pandemic has provided an unintended global 'field experiment', and new unforeseen issues have emerged, such as the phenomenon of 'Zoom-fatigue', or the prevalence of psychological problems related to social isolation in virtual settings (Brunsbach, Kattenbach \& Weber, 2021). Further, existing concepts have changed their meaning: Earlier notions of 'hybrid work contexts' referred to potential ways of switching between online and offline settings at different points in time. In contrast, in 'postpandemic' discussions, hybrid work scenarios refer to simultaneous applications of online and offline collaboration. Such emerging topics devise important avenues for future conceptual and empirical research.

\section{References}

Aroles, J., Mitev, N., \& de Vaujany, F.-X.(2019). Mapping Themes in the Study of New Work Practices. New Technology, Work and Employment 34(3), 285-299.

Banks, G. C., Dionne, S. D., Sayama, H., \& Schmid Mast, M. (2019). Leadership in the digital era: Social media, big data, virtual reality, computational methods, and deep learning. The Leadership Quarterly, 30(4), I-II.

Bergmann, F. (1994). Neue Arbeit - Das Konzept und seine Umsetzung in der Praxis. [New Work]. In: W. Fricke (Ed.): Jahrbuch Arbeit und Technik 1990, p. 71-80. Bonn: J.H.W. Dietz Nachf.

Bergmann, F. (2004). Neue Arbeit, neue Kultur. [New Work New Culture] Freiburg: Arbor Verlag.

Brunsbach, S.; Kattenbach, R.; Weber, I. (2021): Keep on Learning. Academic Exhaustion and Teaching Evaluation in Digital Times. Journal of Political Science, 31(4).

Helfat, C. E., \& Martin, J. A. (2014). Dynamic managerial capabilities: Review and assessment of managerial impact on strategic change. Journal of Management, 41(5), 1281-1312.

Kossek, E. E., \& Lautsch, B. A. (2018). Work-life flexibility for whom? Occupational status and work-life inequality in upper, middle, and lower level jobs. The Academy of Management Annals, 12(1), 5-36.

Kump, B. (2019). Beyond power struggles: A multilevel perspective on incongruences at the interface of practice, knowledge, and identity in radical organizational change. The Journal of Applied Behavioral Science, 55(1), 5-26. 
Leiponen, A. E., Thomas, L. D. W., Forman, C., McElheran, K., Nagaraj, A., \& Tambe, P. (2016). Digitization and strategy: Competitive implications of digital technologies and big data. Academy of Management Proceedings, 2016(1).

Noe, R. A., Clarke, A. D., \& Klein, H. J. (2014). Learning in the twenty-first-century workplace. Annual Review of Organizational Psychology and Organizational Behavior, 1(1), 245-275.

Orlikowski, W. J., \& Scott, S. V. (2008). Sociomateriality: Challenging the separation of technology, work and organization. Academy of Management Annals, 2(1), 433-474.

Raghuram, S., Hill, N. S., Gibbs, J. L., \& Maruping, L. M. (2019). Virtual work: Bridging research clusters. Academy of Management Annals, 13(1), 308-341.

Robertson, B. J., (2015). Holacracy: The Revolutionary Management System that Abolishes Hierarchy. London: Penguin UK.

Sheninger, E. (2019). Digital leadership: Changing paradigms for changing times. Thousand Oaks: Corwin Press. 